\title{
OS ANOS TRINTA NAS MEMÓRIAS E NO ARQUIVO DE PAULO DUARTE: UMA CULTURA POLÍTICA DE OPOSIÇÃO A GETÚlIO VARGAS
}

The 1930s in Paulo Duarte's memoirs and archive: a political culture of opposition to Getúlio Vargas

Los años treinta en las memoria y los archivos de Paulo Duarte: una cultura política de oposición a Getúlio Vargas

CAROLINA SOARES SOUSA ${ }^{\mathrm{I} *}$

DOI: http://dx.doi.org/10.1590/S2178-149420200003000011

'Escola do Legislativo do Estado de Goiás - Goiânia (GO), Brasil.

*Doutora em História pela Universidade de Braślia (carolina_soaressousa@hotmail.com)

(D) https://orcid.org/0000-0001-5519-471X

Artigo recebido em $1^{\circ}$ de maio de 2020 e aprovado para publicação em 8 de julho de 2020. 


\title{
RESUMO
}

Este artigo tem como objetivo o estudo da atuação política de Paulo Duarte no grupo político de Armando de Salles Oliveira. Priorizaremos seu protagonismo no jogo político regional e nacional nos anos trinta, com destaque para os meses que antecederam o golpe de novembro de 1937. Como se trata de um grupo derrotado, a memória histórica construída acerca dessa experiência ignorou sua especificidade e incorporou-a no discurso homogeneizador e continuísta que conflui e deságua na Era Vargas. É em São Paulo, com o pensamento e ação de Duarte e de seu grupo político, que será desenvolvida com maior expressividade uma cultura política de oposição ao varguismo.

PALAVRAS-CHAVE: Paulo Duarte; anos trinta; cultura política; história; memória; arquivo.

\begin{abstract}
This essay aimed to study the political performance of Paulo Duarte, within the political group of Armando de Salles Oliveira. We intended to focus on his role in the regional and national political game in the 1930s, highlighting the months leading up to the November 1937 coup. As it is a defeated group, the historical memory created on this experience has ignored its specificity and incorporated it into the homogenizing and continuous discourse that has come together and flowed into the "Era Vargas". It is in São Paulo, with the thought and action of Duarte and his political group, that a political culture of opposition to "varguismo" was developed with greater expressiveness.
\end{abstract}

KEYWORDS: Paulo Duarte; 1930s; pollical culture; history; memoires; archive.

\section{RESUMEN}

Este artículo tuvo como objetivo estudiar el desempeño político de Paulo Duarte, dentro del grupo político de Armando de Salles Oliveira. Dimos prioridad a su papel en el juego político regional y nacional en los años treinta, destacando los meses previos al golpe de noviembre de 1937. Como es un grupo derrotado, la memoria histórica construida sobre esta experiencia ignoró su especificidad y la incorporó al discurso homogeneizador y continuo que se unió y desemboca en la "Era Vargas". Es en São Paulo, con el pensamiento y la acción de Duarte y su grupo político, donde se desarrollará con mayor expresividad una cultura política de oposición al "varguismo".

PALABRAS CLAVE: Paulo Duarte; años treinta; cultura política; historia; memoria; archivo. 


\section{INTRODUÇÃO}

pós o fim do regime do Estado Novo, a memória da revolução de 1930 e dos anos que
compreenderam a política de Getúlio Vargas seguiu em permanente construção. Impressiona a quantidade de relatos memorialísticos sobre o período. A visão de que a revolução de 1930 se consumou somente com o golpe de novembro de 1937 foi amplamente difundida pelos próceres do Estado Novo, entre eles políticos, intelectuais e militares que buscaram legitimar o regime com tal discurso. Para os grupos políticos que se sentiram prejudicados e tiveram seus projetos afetados, o passado precisou ser cortado, costurado, recortado e recosturado quantas vezes fosse necessário, em busca de um sentido de orientação sobre os papéis desempenhados durante o largo período, de 15 anos, em que Vargas permaneceu no poder. A preocupação com a gênese do golpe de novembro de 1937 surgiu no fim da década de 1930, quando a fala "oficial e oficiosa" (Borges, 1998) procurou construir a ideia de que a ruptura em novembro de 1937 era uma consequência já projetada pela ruptura de outubro de 1930, um caminho natural e inevitável. Em 1937, o discurso dos vitoriosos ofuscava a existência de diferentes projetos que disputaram o jogo político entre a revolução e o golpe, conferindo ainda modernidade ao projeto político varguista (Pandolfi, 2003).

Se para o senso comum a chamada Era Vargas ainda é vista como um bloco coeso, em que os fatos estão ligados, encadeados numa sequência lógica de acontecimentos, para a historiografia tal abordagem já está devidamente superada. Os 90 anos da revolução de 1930 encontram, hoje, produção historiográfica dedicada aos diferentes grupos que compuseram aqueles anos, com abordagens variadas, desconstruindo a perspectiva homogeneizante do projeto político vencedor. Ainda nos anos 1980, Carlos Alberto Vesentini (1997) defendeu importante tese, A teia do fato, alertando para a necessidade da desnaturalização de uma memória histórica que legitima e justifica o vencedor; impedindo a percepção do vencido, compreendendo que o que fica retido na memória histórica, como resíduo, não são apenas agentes políticos, mas projetos, estes sim os grandes vencidos. Um desses projetos envolve o caso de São Paulo, acertadamente classificado pela historiadora Vavy Pacheco Borges (1979) como a "história de uma esperança e de muitos desenganos", e continua a suscitar questionamentos sobre o jogo político daquele período e sobre como foi possível Vargas estabelecer uma articulação com os grupos políticos predominantes, permanecendo no poder por longo período.

Os itinerários do grupo político de Armando de Salles Oliveira, os armandistas, derrotados com o golpe de novembro de 1937, foram marcados fundamentalmente por quatro momentos do jogo político nacional. Os três primeiros momentos são: de apoio a Getúlio 
Vargas durante a Revolução de 1930, de oposição entre 1930 e 1932 - com a Revolução Constitucionalista - e, novamente, de apoio com a ascensão de Armando de Salles Oliveira à interventoria de São Paulo, de 1933 a 1936. Entretanto, o quarto momento da relação será marcado por novo distanciamento, traduzido na declarada oposição a Vargas, com a candidatura de Armando de Salles Oliveira à presidência da República para o pleito que ocorreria em 3 de janeiro de 1938. Trata-se de posição de confronto por parte da elite política paulista armandista, que tem como desfecho o golpe de novembro de 1937, estendendo-se por todo o exílio de Armando de Salles Oliveira e outro membro importante do grupo, Paulo Alfeu Junqueira Duarte. É em São Paulo, com o pensamento e a ação de Paulo Duarte e de seu grupo político, que uma cultura política de oposição a Getúlio Vargas será desenvolvida com maior expressividade. Nesse sentido, não estamos lidando apenas com ações de oposição política exercidas por Paulo Duarte e pelos demais membros do grupo, expressada em atuações localizadas em determinado período, mas sim com uma cultura política de oposição desenvolvida por meio dos ressentimentos compartilhados com relação a Getúlio Vargas, representando um fator de agregação e de sentimento de solidariedade no interior de um grupo político (Zioli, 2010). No caso de Paulo Duarte, a visão negativa da presença de Vargas como homem público ordenou o sentido de sua militância política e de sua vida. Duarte manteve inalterada sua posição de oposição e buscou compreender e explicar as razões da aproximação de membros do seu grupo, como Armando de Salles Oliveira, com Vargas (Sandes, 2012).

Em 1936, Paulo Duarte e Armando de Salles Oliveira acreditavam ser possível vencer o pleito eleitoral marcado para janeiro de 1937 e organizar o país com base em um projeto político oriundo de São Paulo. Encontramos tais aspirações no empreendimento memorialístico e arquivístico realizado por Paulo Duarte, a fim de construir uma memória histórica que justificasse a derrota de seu grupo político e projeto. As memórias registradas por Paulo Duarte e 0 arquivo político por ele organizado constituíram fontes importantes para a compreensão do pensamento do grupo político aglutinado em torno da liderança de Armando de Salles Oliveira. A escolha por Paulo Duarte como porta-voz do grupo armandista ancorou-se em meu argumento em defesa de outra possibilidade de leitura das experiências políticas ocorridas após a revolução de 1930, uma leitura que prioriza os grupos políticos que tiveram seus projetos derrotados.

\section{PAULO DUARTE: MEMÓRIA E ARQUIVO}

aulo Duarte iniciou a escrita do seu projeto memorialístico na segunda metade da década
de 1960, e a nova onda ditatorial que assolava o país com o golpe de 1964 pode ter ser- 
vido de impulso para lembrar os acontecimentos da década de 1930 e a violência estado-novista. Intitulado como Memórias, o trabalho resultou em nove volumes, com cerca de três mil páginas contemplando sua vida pessoal e política, publicados entre 1974 e 1979. A empreitada teve auxílio de um arquivo político, cuidadosamente reunido, guardado e organizado pelo próprio memorialista ao longo de sua vida. 0 termo arquivo político foi usado por Paulo Duarte já no prefácio de seu primeiro volume de memórias (Duarte, 1974). Entendemos que 0 arquivo é político não apenas porque é formado de documentos pessoais, mas também porque reúne documentos de outros membros de seu grupo, documentos públicos e, sobretudo, porque são registros políticos. 0 material revela preocupação em construir uma memória e posicionar-se politicamente sobre os acontecimentos vividos e testemunhados. Uma questão impulsionou-me a pesquisar o empreendimento memorialístico e arquivístico de Paulo Duarte: de que modo o seu arquivo contempla uma memória particular sobre sua trajetória e a de seu grupo, possibilitando outra leitura para os embates políticos dos anos trinta? A primeira coisa que precisamos fazer é localizar as ações políticas efetivas de Paulo Duarte e compreender a dimensão de seu esforço em arquivar.

A historiadora Marli Hayashi (2010) comparou Duarte a Dom Quixote, alguém que passou sua vida brincando de sonhar sonhos impossíveis. Entre esses sonhos, estavam 0 Departamento de Cultura, o Instituto de Criminologia, o Museu do Homem Americano, a Revista Anhembi e o Instituto de Pré-História. Alguns projetos ficaram apenas no plano de aspiração, outros chegaram a ser executados, mas foram interrompidos, provocando uma frustração que fica aparente em seus relatos. Nas memórias de Duarte, há grande destaque ao seu envolvimento com o grupo político de Armando de Salles Oliveira durante a década de 1930. Este tinha conseguido ascender ao governo de São Paulo como interventor, indicado por Getúlio Vargas. Com essa ascensão e a fundação do Partido Constitucionalista', o grupo começa a se consolidar no cenário político nacional. A relação de Duarte com o grupo possibilitou que parte de seus projetos fossem realizados, mas é também a responsável pela interrupção de outros. Ainda mais, é importante destacar que foi com a idealização desses projetos que Duarte teceu uma impressionante rede de sociabilidade com intelectuais e políticos de sua época. Se o vínculo com a comunidade política do jornal $O$ Estado de $S$. Paulo² o colocou na mira do governo Vargas, provocando seus dois exílios, também possibilitou sua participação em episódios da vida cultural e política paulista. Essa ligação pode ser considerada uma expressão de sociabilidade que Jean-François Sirinelli (2003) chamou de "sensibilidade ideológica ou cultural comum", em torno da qual um grupo de intelectuais ou políticos se organiza, partilhando dos mesmos projetos. 
Todo grupo de intelectuais organiza-se também em torno de uma sensibilidade ideológica ou cultural comum e de afinidades mais difusas, mas igualmente determinantes, que fundam uma vontade e um gosto de conviver; São estruturas de sociabilidade difíceis de apreender, mas que o historiador não pode subestimar (Sirinelli, 2003: 257).

No prólogo do primeiro volume de suas memórias, Raízes profundas (1974), Duarte escreveu as "Razões de defesa por ter vivido", justificando a necessidade de relatar determinados episódios por ele vivenciados. Para o memorialista, apenas uma vida de ações, coerente com o posicionamento político daquele que resolve escrever suas memórias, era digna de ser contada. A sua vida, sem falsa modéstia, deveria ser objeto de uma escrita memorialística:

Muita gente não precisava nem de escrever memórias. São amnésicos ou, melhor, deviam ser amnésicos, mas isso no sentido de possuir e não no de ter perdido o próprio passado. Porque não têm o que contar ou nem o devem contar. Vida confidencial ou insípida, medíocre, vegetativa ou inconfessável, ou nem nada de interessante a não ser maldades ou manhas, complementos ou atributos. Outros não as escrevem para não lembrar coisas que, no próprio interesse, devem mesmo ser conservadas em silêncio. 0 passado faz medo ou desagrada a muitos (Duarte, 1974: 1).

Mas somente uma escrita memorialística, ancorada em lembranças, não era suficiente para garantir o caráter de verdade e cientificidade que Duarte almejava. Ainda mais, não era suficiente para contestar a versão do projeto político vencedor. Uma documentação sólida, rica em diversos personagens, auxiliaria da forma necessária. Duarte começou a guardar documentos com maior cuidado após o primeiro exílio sofrido, consequência da derrota dos paulistas na revolução de 1932. A consciência de poder perder tudo em pouco tempo o fez ter cautela extremada e carregar seu arquivo político, sempre em construção, durante seu segundo exílio. Ao realizar pesquisa no Fundo Paulo Duarte 3 , foi-nos possível perceber algumas preocupações importantes e reveladoras. 0 zelo em guardar cartas, documentos, diários, resultou em vinte e duas pastas divididas em vida pessoal, política, produção intelectual, recortes de jornais, entre outros. No esforço de organizar o passado em documentos, seus e de seus pares, Paulo Duarte revela a vontade de que sua memória individual seja lida como memória coletiva, a memória do grupo. 0 memorialista também organizou dossiês políticos sobre Armando de Salles Oliveira, a campanha eleitoral de 19374, o Partido Constitucionalis$\mathrm{ta}^{5}$ e Ademar de Barros. Tantos documentos de terceiros revelam uma troca entre lembranças pessoais e acontecimentos vividos pelo grupo político de $O$ Estado de $S$. Paulo durante os anos trinta. Lembrando Halbwachs (2004), há acontecimentos que modificam a existência de todos os membros de um grupo político, oferecendo a todos um ponto de referência em comum. É assim que Duarte relata a experiência vivida pelo grupo nos anos trinta. 
A narrativa memorialística de Paulo Duarte é frequentemente interrompida pela apresentação de cartas trocadas entre seus pares, para que possa melhor esclarecer e, o mais importante, comprovar o que está sendo narrado. No arquivo, as cartas estão divididas entre "correspondências enviadas", "correspondências recebidas" e "correspondências de terceiros". Armando de Salles Oliveira, por exemplo, correspondeu-se principalmente com Vicente Ráo, Vivaldo Coaracy, Antônio Mendonça e Arnon de Mello, membros de seu grupo político e fundamentais no desenvolvimento da campanha eleitoral para a presidência no ano de 1937. 0 uso dessas correspondências é seu suporte documental, balizando a organização de uma memória. Nesse sentido, Paulo Duarte defendia que, ao contrário do tradicionalmente praticado,

a verdadeira história não é contada pelos documentos oficiais, mas pela correspondência e os diários deixados por grandes figuras, testemunhas exatas de acontecimentos ou nomes notáveis na política e na literatura, como Saint Simon, por exemplo, cujos quase duzentos cadernos de memórias levantavam a época neles contidas (Duarte, 1974: 2).

Sob tal perspectiva, e mobilizado pela proposta de escrever a verdadeira história de sua época e de sua vida, que parecem dele indissociáveis as correspondências de seu arquivo pessoal representam a principal fonte, exaustivamente apresentada, dos seus nove tomos de memórias. 0 uso da correspondência pessoal, bem como de um conjunto de cartas de membros do grupo armandista, revela-nos os objetivos e o modo como Paulo Duarte construiu e organizou suas memórias, integradas às de seu grupo político e intelectual. Nelas encontramos a construção dos projetos e trajetórias do grupo (Gomes e Schmidt, 2009: 7). Há a visível preocupação em conferir visibilidade à sua atuação política nos complexos acontecimentos dos anos 1930-1945. Por que Paulo Duarte documentou suas experiências pessoais e políticas, constituindo um acervo de tamanho considerável e que tem servido para alimentar pesquisas e fundamentar estudos a respeito da história política de São Paulo e do Brasil? Pensamos na importância desse material para fundamentar análises sobre a atuação do grupo político do qual Paulo Duarte foi integrante aguerrido e sobretudo um "guardião" da memória de tal atuação, que ele reputa como a "verdade" acerca das experiências vividas naquele período turbulento de nossa história. Em um projeto memorialístico, história e memória trabaIham juntas, revelando-se como um esforço de construção de um lugar de memória. 0 arquivo não teve apenas a função de armazenar organizadamente a documentação cuidadosamente recolhida, reunida e guardada por Paulo Duarte ao longo de sua vida. Mais que isso, o arquivo conta sua história. 0 passado arquivado e relatado em suas memórias poderia ser "recuperado" tal como ocorreu e devidamente comprovado pelas fontes ali organizadas. Arquivo, 
memória e história confundem-se, entrelaçam-se, imbricam-se nesse exercício de preservação de um acervo, de montagem de um cenário, de escrita da "verdadeira" história.

Em 1970, Paulo Duarte encontrava-se mais uma vez com sérias dificuldades financeiras e negociou com o reitor Zeferino Vaz a venda de sua biblioteca e a doação de seu arquivo para a Universidade Estadual de Campinas (Unicamp). Após sua morte, o arquivo seguiu primeiro para o Arquivo Central do Sistema de Arquivos (Siarq) e, posteriormente, em agosto de 1994, para o Centro de Documentação Alexandre Eulalio (CEDAE), onde se encontra hoje em dia, juntamente com a biblioteca, ambos catalogados por Duarte. Uma visão de seu legado documental tornou-se possível após a aquisição do arquivo pelo CEDAE, onde foi constituído o Fundo Paulo Duarte. Aqui a noção de legado está de acordo com as reflexões de Luciana Quillet Heymann (2005b): os processos de selecionar e reunir os documentos que devem ser guardados, seus e de seus pares, e de constituir um arquivo que fale em nome do grupo, revela que Paulo Duarte não quer apenas ser lembrado, mas sim intervir em qual história será preservada sobre sua atuação política. Ao vender a biblioteca para a Unicamp, exigindo que o arquivo ficasse nela para que não corresse o risco de se dispersar (Duarte, 1974), Duarte reconhece-se em suas memórias como peça importante da história de São Paulo e do Brasil durante os anos 1930, cuidando para que seu legado e sua interpretação dos fatos passados fossem preservados. Seu arquivo deve ser tomado como objeto histórico, capaz de revelar um projeto político e um ideário comum ao seu grupo. Nesse sentido, o Fundo Paulo Duarte e os nove tomos de memórias funcionam como agentes de mediação entre o passado, o presente e o futuro. Entretanto, é importante ressaltar que a produção de um legado não depende exclusivamente da intenção do indivíduo que quer ser lembrado (Heymann, 2005a), tanto que o legado de Getúlio Vargas foi explorado exaustivamente enquanto outras trajetórias políticas foram relegadas ao esquecimento.

Cientes dos embates e disputas entre memória e história, e também de suas relações e intercessões, não buscamos neste artigo verificar a "verdade" dos relatos de Paulo Duarte. Procuramos justamente apreender o uso que ele faz do discurso da memória para lembrar, precisar e legitimar sua história acerca de sua atuação e localização na política. Nossa preocupação é com a análise crítica das memórias de Paulo Duarte, tentando compreender como ela guarda um propósito. Interessa-nos, assim, apreender seu modo de ver a experiência política sua e do grupo político do qual fazia parte, o que incluiu conhecer as suas condições de produção, sinalizadas na cultura política da década de 1930 nos jogos de poder, nas linguagens compartilhadas, nas estratégias de luta e de atuação, nos significados conferidos às experiências vivenciadas e às narrativas produzidas sobre elas, já que foram dispostas em imenso arquivo e expressas em cerca de três mil páginas. Apreender a memória histórica cui- 
dadosamente construída por Paulo Duarte oferece outra leitura para o jogo político paulista e nacional durante os anos trinta.

O prólogo "Razões de defesa por ter vivido", que abre os nove tomos de memórias de Paulo Duarte, é bastante revelador dos propósitos do autor. Como avalia Beatriz Sarlo (2007: 51), "o discurso da memória transformado em testemunho tem a ambição da autodefesa: quer persuadir o interlocutor presente e assegurar-se uma posição no futuro". Parece-nos ser esse 0 caso de Paulo Duarte no que diz respeito às suas memórias sobre sua atuação política no seu grupo: tem a "ambição da autodefesa" e também a de persuadir o interlocutor presente, de assegurar para si um lugar na história.

A seguir, para tentar compreender como Paulo Duarte lida com a construção de memória histórica sobre sua atuação e a atuação de seu grupo político, escolhemos tratar de um dos episódios que marcaram as memórias de Paulo Duarte, aferindo os relatos com os documentos encontrados no arquivo: o golpe de novembro de 1937. É ao golpe desferido por Getúlio Vargas que Paulo Duarte atribui a responsabilidade pela interrupção e frustração de seus projetos com o grupo político de Armando de Salles Oliveira. O projeto político do grupo foi iniciado logo após a revolução de 1932, quando Armando de Salles Oliveira foi indicado por Getúlio Vargas para assumir a interventoria de São Paulo. Consistia em transformar São Paulo numa espécie de vitrine do que seria o Brasil sob a gestão do grupo político armandista. Paulo Duarte registra em suas memórias, fiado em documentos reunidos em seu arquivo, ideias discutidas por seu grupo político sobre o modelo de Brasil que queriam desenvolver. Entretanto, as eleições presidenciais marcadas para janeiro de 1938 moveram a roda da história e as cartas da política paulista foram, novamente, embaralhadas.

\section{O GOLPE DE NOVEMBRO DE 1937 NAS MEMÓRIAS DE PAULO DUARTE}

$\mathrm{E}$

ntre 1936 e 1937, a campanha política para eleger Armando de Salles Oliveira presidente do Brasil estava intensificada. 0 cenário eleitoral ainda contava com os candidatos José Américo de Almeida, apoiado pelo Partido Republicano Paulista, e Plínio Salgado, da Ação Integralista Brasileira6. Ilka Stern Cohen (1997: 189) apontou que o grupo político de Salles Oliveira arquitetou uma estratégia de campanha eleitoral na qual se buscava disseminar um modelo de governo capaz de retirar o Brasil da crise política em que se encontrava. Crise, essa, creditada a um suposto "perigo vermelho", "perigo verde" e a uma possível "volta à ditadura" conduzida por Vargas. Paradoxalmente, ao defender seu projeto político, forjado em um modelo capaz de salvar o Brasil, o discurso armandista aproximava-se do discurso de 
defesa do regime do Estado Novo quando instalado, ou seja, aproximava-se do seu maior opositor, Getúlio Vargas.

Quando os membros do grupo armandista foram surpreendidos com a notícia dos planos de Getúlio Vargas para cancelar o pleito eleitoral e permanecer no poder, decidiram não mais recuar e iniciaram uma oposição explícita, aprovando uma carta redigida por Armando de Salles Oliveira que denunciava a possibilidade de um golpe de Estado. Ao fazer isso, rompiam o silêncio político até então praticado em relação ao que o grupo considerava desmandos do governo Vargas. No entanto, era tarde para agir e resistir, já que o golpe os pegou de "surpresa" e sem consolidar as alianças ensaiadas e anunciadas ao longo da campanha política praticada naquele ano (Duarte, 1977). 0 grupo descobriu que se encontrava isolado nesse pesado jogo contra o governo Vargas, sem o necessário apoio político e militar. Não é nosso objetivo no espaço deste artigo detalhar as alianças políticas que levaram ao golpe da perspectiva da historiografia, mas sim apresentar a visão de Duarte em suas memórias a respeito do acontecimento, principalmente nos dias que antecederam o golpe.

Apesar de Paulo Duarte afirmar que o evento surpreendeu a todos, o próprio jornal O Estado S. Paulo, desde setembro de 1937, publicou artigos insinuando um possível movimento continuísta por parte do governo Vargas. Uma hipótese que podemos levantar para desconstruir a ideia de assentimento ou silêncio diante da atuação de Vargas é pensar que o grupo armandista usou como estratégia para combater um possível golpe a intensificação da campanha eleitoral. Entretanto, o crescente apoio à candidatura de Armando Salles Oliveira e da campanha eleitoral não foi suficiente para assegurar que a sucessão presidencial ocorresse democraticamente; pelo contrário, acelerou os planos continuístas de Vargas que, ao sentir-se ameaçado, contra-atacou, articulando o golpe de Estado.

0 tema do debate sucessório surgiu pela primeira vez nos diários de Getúlio Vargas, vinculado aos comentários públicos feitos pelo governador constitucional do Rio Grande do Sul, Flores da Cunha. Desde a instalação do governo provisório, os gaúchos estavam frustrados com a política centralizadora adotada por Vargas. Tal postura não estaria de acordo nem com as práticas tradicionais nem com a plataforma apresentada e defendida pela Aliança Liberal em 1930, em prol da qual os gaúchos haviam lutado e colaborado para retirar o paulista Washington Luís do poder (Camargo, 1989). No arquivo de Duarte se encontram cartas trocadas com Armando de Salles Oliveira sobre um possível apoio de Flores da Cunha à sua candidatura. Getúlio Vargas até mesmo registrou em seu diário alguns encontros com Armando de Salles Oliveira durante o ano de 1937. Nas ocasiões, tentou dissuadi-lo da candidatura, revelando seu temor por uma vitória paulista. 
Ao escrever Ofício de trevas, seu sexto volume de memórias, publicado em 1977, Paulo Duarte, contemporâneo dos desfechos do golpe de 1937, relembra a campanha eleitoral de Armando de Salles Oliveira, deflagrada em concomitância à ação dos militares e do governo varguista ${ }^{7}$ direcionada para o golpe. Segundo seu relato, a movimentação do Exército foi decisiva para a deflagração do golpe e não a antecipação da sucessão presidencial:

Sempre os militares inquietando a nação num momento em que se dava a prova mais segura de que nada perturbava a calma do País, que apenas manifestava seu entusiasmo pelas próximas eleições. [...] Chego a pensar se, antes de meter o ombro a qualquer importante problema nacional, como quer Armando de Salles Oliveira, se devia, primeiro, reeducar e disciplinar o Exército. Mas quem será capaz de pôr o guizo no pescoço do gato? (Duarte, 1977: 1).

Para Duarte, ainda que muitos políticos soubessem sobre o que estava prestes a acontecer quanto aos rumos políticos do país, os mesmos estavam presos "aos nós apertados com que Getúlio Vargas sabia manietar os seus asseclas" (Duarte, 1977: 2), entre eles os militares, que estariam servindo aos interesses do chefe do governo federal. A avaliação do memorialista sobre o papel dos militares é simplista, colocando-os, a princípio, apenas como marionetes de Vargas, no entanto sabemos que a participação dos militares, por intermédio de Góes Monteiro e o General Dutra, foi fundamental para a elaboração e a deflagração do golpe de novembro de 1937. Vargas também serviu ao interesse dos militares.

Dos "asseclas", Paulo Duarte excluía Armando de Salles Oliveira, visto por ele como um "estadista" e não um político submisso com quem compartilhava um projeto político de dominação nacional. Armando de Salles Oliveira era considerado um político de visão, que sabia dar "passos largos", pragmático. São esses atributos que Paulo Duarte utiliza para explicar, convenientemente, a composição do grupo paulista com Vargas. Seria apenas uma tática do jogo, um caminho para alcançar o pretendido, no caso, a sucessão presidencial. Já outros políticos seriam "desavergonhados", na avaliação de Paulo Duarte, haja vista o silêncio da Câmara diante da mensagem de "estado de guerra" encaminhada a ela por Vargas em 1937:

Assim, permaneceram eles firmes e indiferentes ao futuro e aos resíduos da própria dignidade que ainda lhes sobravam quando, ao amanhecer de 2 de outubro de 1937, antes de voltar 0 país da surpresa dos primeiros boatos, chega à Câmara dos deputados a mensagem de Getúlio solicitando o estado de guerra (Duarte, 1977: 2).

0 estado de guerra foi decretado no início de outubro pelo prazo de três meses, o período que faltava para a execução da eleição presidencial, evidenciando tratar-se de medida cuja pretensão era a de cercear a propaganda política, como denunciaram os oposicionistas a Vargas. Segundo Duarte, o líder paulista na Câmara Valdemar Ferreira subiu novamente à 
tribuna alegando a inconstitucionalidade do pedido, que só podia ser admitido em caso de grave comoção interna, situação que não se verificava no Brasil naquele momento. 0 deputado também denunciou o Plano Cohen ${ }^{8}$ e prosseguiu divulgando algo mais que estava para acontecer:

Há ainda um aspecto gravíssimo que é preciso repisar, diz Valdemar Ferreira. Até pelos corredores da Câmara certos arautos asseguram: não haverá eleições a 3 de janeiro; o mandato do presidente da República será prorrogado e o dos deputados também. Há um programa de subversão que está sendo friamente executado. "É preciso denunciá-lo ao País" — Valdemar alteia a voz — "e eu tomo sobre mim a responsabilidade de denunciá-lo!" — diz Valdemar Ferreira numa tempestade de aplausos. - "E o programa vai ser executado por etapas. Hoje é o estado de guerra. Se não o votarmos será a dissolução da Câmara. Mas dissolvida será ela de qualquer maneira. Os fatos confirmarão o que acabo de dizer e faço votos, os melhores votos, para que seja desmentido o que anuncio (Duarte, 1977: 2).

0 deputado Valdemar Ferreira defendia que o governo deveria prestar as devidas informações ao Poder Legislativo para que os deputados pudessem se posicionar em relação à situação enfrentada. Além disso, a Câmara também deveria ser informada dos termos da representação militar, pois só assim teria condições de votar, fundamentada e conscientemente, o estado de guerra. Todavia, a maioria dos deputados permaneceu em silêncio, "nesse diapasão, num ambiente de silêncio perplexo. 0 silêncio dos covardes" (Duarte, 1977: 3). Para Duarte, o país havia sido apanhado de surpresa, não havia nenhum indício de comoção interna que de fato justificasse o pedido, daí a posição cautelosa e desconfiada daquele deputado da oposição. 0 que parecia seriamente ameaçado naquele momento era o regime que vigorava, possibilidade que foi contida com a declaração do estado de guerra pelo período de três meses, ou seja, até a data marcada para as eleições.

Ao relembrar os acontecimentos que precederam o golpe de 1937, Paulo Duarte destaca a primeira "rachadura no bloco político de Armando de Salles Oliveira", sinal visível do processo de seu enfraquecimento político e da fragilidade dos acordos políticos e dos apoios firmados, mas não cumpridos. Além disso, ressalta a incoerência do pedido de estado de guerra apresentado pelo Ministério da Justiça na figura de José Carlos Macedo Soares, cujo discurso, até então, afirmava justamente o contrário, que reinava a "mais absoluta calma" no país:

Há poucos dias o ministro da Justiça declarava em S. Paulo que o País estava na mais absoluta calma e que não havia nada que justificasse qualquer inquietação. Apenas três dias depois, surge esse estranho e misterioso relatório dos ministros militares e é o mesmo ministro da Justiça que, encaminhando-o, solicita o estado de guerra! E um pedido dessa ordem vem desacompanhado de qualquer documento! Onde está essa alegada comoção intestina? Comoção 
intestina é coisa que se vê e sente, é coisa palpável, e o país inteiro só dela toma conhecimento por uma notícia enviada pelo ministro da Justiça ao Parlamento e desacompanhada da menor prova (Duarte, 1977: 3).

Mas as denúncias e apelos dos constitucionalistas não surtiram efeito no sentido de angariar apoio por parte dos políticos e tampouco dos militares. No Senado, o projeto para a decretação do estado de guerra foi aprovado por 22 votos contra três, dados por Paulo Morais Barros, Cesário de Melo e Jerônimo Monteiro. Esses três políticos, segundo Paulo Duarte (1977: 6), " não se haviam submetido ao terrível processo de emasculação moral". Aprovado o projeto, Getúlio Vargas imediatamente baixou o decreto que declarava o estado de guerra pelo prazo de 90 dias em todo o território nacional, sob a alegação de "comoção intestina grave", articulada no país com a finalidade de subverter as instituições políticas e sociais. Com o decreto, suspendiam-se todas as garantias públicas e privadas, que era finalmente 0 que se tinha em vista com a declaração do estado de guerra. Nessa suspensão, evidenciava-se o projeto varguista de continuar no poder sob o argumento de que necessitava de tempo e dessas condições excepcionais para realizar as reformas exigidas para a modernização do país. Durante 90 dias o Brasil permaneceria, na avaliação de Paulo Duarte (1977: 6), " no rol das nações politicamente mais atrasadas do mundo, sob uma medida de exceção", algo que somente uma ameaça de invasão estrangeira ou a máxima calamidade interna poderia justificar, mas que foi declarado com base em justificativa infundada, sem o peso exigido para tal.

As cisões, traições, recomposições e alianças começaram a surgir, redesenhando os cenários políticos nacional e paulista. Afirmava-se que o governador de São Paulo, Cardoso de Melo Neto ${ }^{9}$, apesar de ter sido antigo membro do Partido Democrático e de ter aderido posteriormente ao Partido Constitucionalista, preparava o seu rompimento com Armando de Salles Oliveira. Tudo indicava que, no caso de um golpe de Estado, Cardoso de Melo Neto permaneceria à frente do governo paulista com o apoio de Alcântara Machado. Vargas entregaria a ele a direção da política em São Paulo. Duarte registrou que o próprio Fábio Prado já havia alertado a todos sobre essa possível traição:

"O Cardoso", dizia ele, "fatalmente acabará brigando com o Armando. Em primeiro lugar, porque ele anda furioso com a intromissão dos agentes diretos do Armando em seu governo" — 0 que era verdade - "e, em segundo lugar, um governador de Estado por muito digno que seja quer fazer o seu governo e não governar dirigido de longe pelo seu antecessor, embora essa direção fosse apenas para não quebrar uma linha política preestabelecida" (Duarte, 1977: 8).

Percebemos que Armando de Salles Oliveira também intervinha na administração do governo que ele entendia estar subordinado a ele. Todavia, mesmo diante da decretação 
do estado de exceção, Armando de Salles Oliveira ainda não se dava por vencido. Em 6 de outubro, o candidato paulista anunciou uma caravana à Bahia. De acordo com Paulo Duarte 1977), como o norte era a região estratégica de José Américo de Almeida, candidato de Getúlio Vargas, o paulista Armando de Salles Oliveira planejava ir não apenas à Bahia, mas também estenderia sua viagem a Pernambuco, ao Maranhão e à Paraíba, regiões de domínio getulista10, "para cutucar a onça na sua própria toca" (Duarte, 1977: 9). Essa disputa acirrada é objetivamente identificada por Getúlio Vargas, que faz uma precisa avaliação do momento político atravessado pelo país após a decretação do estado de guerra: o de complicação do panorama político. Nos seus registros, o presidente assinala o seguinte:

(13 a 15/10/1937) 0 panorama da vida política no Brasil vai se complicando. Os partidários dos dois candidatos começam a vacilar. 0 Sr. Armando Sales, perdida a esperança na vitória, pensa delegar poderes ao governador do seu estado para tratar com o de Minas a escolha de um terceiro candidato. Na Câmara, uma certa corrente de opinião trata da prorrogação dos mandatos. Entre os militares, há um certo grupo partidário do Sr. Armando Sales que disfarça sua atitude, manifestando-se contrário às medidas tomadas pelo governo. 0 ministro da guerra, porém, prepara com decisão a marcha dos acontecimentos. Assinei dois decretos requisitando as polícias militares de São Paulo e Rio Grande (Vargas, 1995: 74).

Com efeito, com o decorrer dos dias e da campanha eleitoral, a situação política do país, que permanecia em estado de guerra, complicou-se intensamente. Em 19 de outubro, 0 governo federal requisitou, isto é, colocou à disposição das forças federais, a Força Pública de São Paulo e a Brigada Estadual do Rio Grande do Sul. Tratou-se de enérgica e rápida reação do governo Vargas contra uma possível união armada entre São Paulo e Rio Grande do Sul. Tal iniciativa provocou uma reação até então inesperada por parte de Flores da Cunha: o governador rio-grandense renunciou e buscou refúgio em Montevidéu, no Uruguai. Era a atitude que o governo Vargas esperava. Afinal, o lugar do ferrenho opositor, Flores da Cunha, foi ocupado pelo interventor nomeado por Vargas, o general Daltro Filho. Este, finalmente, "conseguiu um governo estadual!" , comentou Paulo Duarte, que criticava Dutra desde a Revolução de 1930, alegando que ele teria interesse em ascender ao poder a qualquer custo. A União Democrática Brasileira agiu imediatamente. Três dias após a fuga de Flores da Cunha, requereu ao Tribunal Eleitoral o registro da candidatura de Armando de Salles Oliveira como candidato à presidência da República. Entretanto, o homem forte da oposição a Vargas em seu projeto continuísta, Flores da Cunha, já estava no exílio.

0 ambiente político era, pois, de grande inquietação, com a intriga no seio do Exército, as pressões dos tenentistas, dos partidários de José Américo de Almeida, da oposição dos paulistas, insistindo e disseminando a propaganda política da candidatura de Armando de Salles 
Oliveira. Os boatos eram de que não haveria eleições em 3 de janeiro; falava-se também na prorrogação do mandato do presidente da República — boatos que se intensificaram quando alguns círculos políticos ligados ao candidato José Américo de Almeida anunciaram a retirada de sua candidatura. Não obstante esse movimento de debandada, Armando de Salles Oliveira seguiu firme em sua campanha política, com o apoio do grupo d'O Estado de S. Paulo e a simpatia de um grupo de militares que disfarçava sua posição de apoio à candidatura paulista, "manifestando-se contrário às medidas tomadas pelo governo Vargas" (Duarte, 1977: 74).

Não por acaso, por ocasião das eleições para a sucessão presidencial, o jornal $O$ Estado de S. Paulo voltou a publicar em seu interior o "Jornal do PC", uma espécie de caderno político do Partido Constitucionalista que havia sido criado na época das eleições para a Assembleia Estadual Constituinte, em 1934¹. Fonte importante para pesquisa da cultura política paulista nos momentos que antecederam o golpe, o caderno era reproduzido também em outros grandes jornais de São Paulo e do Rio de Janeiro ${ }^{12}$. A campanha eleitoral seguia e, não fossem os planos que estavam sendo articulados concomitantemente a ela por parte do presidente Getúlio Vargas, alguns dias depois outro presidente seria escolhido para governar o país.

Paulo Duarte comenta os bons resultados numéricos conseguidos graças à campanha eleitoral realizada pelo Partido Constitucionalista. Os dados até aquele momento eram de 850 mil eleitores que se haviam alistado para votar. 0 alistamento eleitoral da população apta a votar era uma das bandeiras defendidas pelas caravanas que o Partido Constitucionalista realizou com Armando de Salles Oliveira pelo país durante a campanha eleitoral. No arquivo de Paulo Duarte há registros de que essas caravanas percorreram a Região Nordeste, onde Salles Oliveira não tinha grande apoio em razão da candidatura de José Américo de Almeida. No entanto, como a campanha eleitoral foi precocemente interrompida, o plano de percorrer todo o território nacional com as caravanas, divulgando o programa político do partido e 0 pensamento de Armando de Salles Oliveira, não pôde ser completamente executado.

No pesado jogo político do momento, uma viagem do deputado Negrão de Lima ${ }^{13}$ ao Nordeste do país causou ainda mais inquietação em Paulo Duarte em razão dos objetivos associados à iniciativa. Na avaliação dele, a viagem daquele deputado à região tinha em vista negociar apoio para a prorrogação do mandato de Getúlio Vargas:

Ao que parece, a missão de Negrão de Lima foi a de propor, a troco de vantagens políticas e pessoais, aos governadores de Estado, a prorrogação do mandato do presidente da República, dilatação por mais seis anos do dos demais governadores, dissolução da Câmara e do Senado e dos legislativos, estaduais, criação de uma câmara corporativa e de um conselho de técnicos que funcionará junto aos ministérios. Puro fascismo, mas Getúlio é apenas um caudilho, esse 
negregado fenômeno sul-americano, herdado dos espanhóis. 0 que ele quer é permanecer no poder. Não tem nenhum gosto ou predileção por este ou aquele regime, desde que seja ele 0 chefe, o presidente, o ditador, o rei, o imperador, o dono (Duarte, 1977: 53).

Paulo Duarte faz também uma avaliação percuciente do que ele entende por pretensões continuístas e caudilhistas de Getúlio Vargas. Na leitura do memorialista, o objetivo de Vargas seria exclusivamente o exercício do poder, sem simpatia por esse ou aquele partido ou candidato, sem predileção por este ou aquele regime. Com tais propósitos e interesses, Vargas atuava disposto a chegar a acordos que the fossem convenientes, como o que havia sido feito com os governos estaduais. Daí enviar o deputado Negrão de Lima para negociar com os governadores, sem que o presidente ficasse comprometido. Em 8 de novembro, José Carlos Macedo Soares demitiu-se do Ministério da Justiça, alegando cansaço. "Cansaço ou remorso?" , perguntava-se Paulo Duarte. Afirmava-se que era por causa do suposto golpe de estado tramado por Getúlio Vargas com o apoio dos militares e de Francisco de Campos ${ }^{14}$. Esse conhecido jurista, fundador da Legião Revolucionária em Minas Gerais e, ao que tudo indicava, vinculado ao integralismo, foi o novo ministro da Justiça de Vargas. Segundo a avaliação de Paulo Duarte, a saída de José Carlos Macedo Soares não significou grande desfalque nas forças do governo federal, mas sua substituição por Francisco Campos foi uma importante virada no jogo político. Paulo Duarte refere-se à entrada de Francisco Campos como uma guinada no jogo político porque foi o novo Ministro da Justiça que, em nome de Getúlio Vargas, articulou o apoio de Plínio Salgado e dos integralistas ao golpe de novembro de 1937. Para convencer Plínio Salgado de que apoiar Vargas era o melhor caminho, Francisco Campos garantiu que o integralismo seria a base da futura organização ditatorial que se almejava construir. Logo em seguida à nomeação de Francisco Campos, os constitucionalistas se reuniram na casa de Armando de Salles Oliveira, no Rio de Janeiro, com integrantes da União Democrática Brasileira, com o intuito de fazer deliberações sobre qualquer possível golpe ou perturbação da ordem. A atmosfera estava pesada.

No dia seguinte, o jornal de oposição paulista, Correio Paulistano, publicou artigo dizendo que a candidatura de Armando de Salles Oliveira estava morta, mas que teria seu atestado de óbito no dia 3 de janeiro, já que as eleições se realizariam, sim, "porque há a assegurá-lo a palavra o chefe da Nação e das mais altas autoridades das Forças Armadas, que não hão de querer o soçobramento da nacionalidade na desordem e na anarquia" (Duarte, 1977: 52). Os constitucionalistas, apesar dos boatos de golpe, tinham razões, embora frágeis, para manterem algumas esperanças quanto à possibilidade das eleições. Ainda na véspera, Armando de Salles Oliveira havia recebido a informação de que um golpe de Estado estava iminente. Todavia, o grupo militar de oposição, formado 
por Eduardo Gomes e outros chefes militares, buscou tranquilizá-lo, afirmando que não havia nenhum ambiente para golpes, não conseguindo, porém, convencê-lo. Afinal, seus informantes haviam confirmado que um golpe estava sendo tramado. Ele decidiu então escrever o manifesto que, na tarde do mesmo dia 9 de novembro, foi lido na Câmara e no Senado; ou seja, jogou sua última cartada.

Segundo Duarte, no âmbito das eleições, o ambiente era aparentemente pacífico, pois, mesmo depois da decretação do estado de guerra, a campanha eleitoral fazia-se em nível intenso e sem que qualquer incidente tivesse sido registrado. Daí a ingenuidade ou dificuldade em acreditar num possível golpe de Estado, mesmo diante das medidas extraordinárias adotadas pelo governo federal. Não haveria aí, por parte de Duarte e dos armandistas, uma falta de visão política? Afinal, as medidas excepcionais que o governo federal tomou contra os Estados demonstravam que não se tratava efetivamente de prevenir-se contra uma ameaça comunista, que era, de fato, inexistente. Na avaliação de Duarte, a medida era um artifício legal para o exercício de um grave desmando, que prorrogava os mandatos e mantinha Getúlio Vargas na presidência da República. Também podemos avaliar o registro de Paulo Duarte, a surpresa diante de um golpe iminente, como uma ingenuidade conveniente, uma vez que políticos paulistas também participaram das medidas que acabaram por distanciar o país de uma eleição democrática. Diante desse quadro, Salles Oliveira redigiu o manifesto, denunciando o golpe que estava sendo articulado sob o regime de exceção do "estado de guerra". Lido no dia 9 de novembro na Câmara e no Senado, o manifesto provocou alguma comoção, sem conseguir, no entanto, cumprir a intenção de seu autor: convencer a maioria dos parlamentares a aderir à proposta armandista.

Assim, o dia 10 de novembro amanheceu calmo em São Paulo, "mas logo no fim da manhã começou a escurecer" (Duarte, 1977: 77). Os boatos tomaram conta do país. Falava-se sobre um golpe de Estado e também sobre um golpe por parte do Exército contra Getúlio Vargas. Apenas à tarde vieram as primeiras notícias concretas. "A realidade era a mais melancólica": os militares, ao invés de "falharem", haviam se aliado a Getúlio Vargas. 0 Parlamento foi fechado no fim da tarde. 0 chefe do governo central falou ao início da noite. Paulo Duarte comentou o discurso de Vargas, encerrando seu capítulo de memórias a respeito dos acontecimentos que antecederam o golpe do Estado Novo:

0 seu discurso foi de um cinismo ímpar. Os militares que o apoiaram e os políticos que o seguiam ou aderiam à última hora ficariam rubros de vergonha se neles houvesse brio pessoal, civil ou militar. Só mesmo um país em pleno esfacelo poderia tolerar semelhante mistificação. Mas tolerou e iria tolerar por oito longos anos de escuridão política, moral e mental (Duarte, 1977: 77). 
As memórias narradas por Paulo Duarte constroem seu compromisso com a defesa dos ideais constitucionalistas e democráticos do grupo político armandista e, sobretudo, um compromisso antivarguista, embora o grupo tenha atuado na administração de uma interventoria indicada por Getúlio Vargas. Em vez de fazer a crítica dessa participação no mínimo questionável de seu grupo político, que optou por fazer uma aliança com Getúlio Vargas, Paulo Duarte significa tal relação como "imperativo" de sobrevivência ou de afirmação do grupo político armandista. A percepção a respeito dos membros de seu grupo político, principalmente de Júlio de Mesquita Filho e de Armando de Salles Oliveira, só mudaria durante o exílio. A expectativa de luta e vitória contra Getúlio Vargas foi frustrada diante da excessiva cautela de seus companheiros. Mas algo que Duarte não avalia é que a expectativa foi também minada pela força de cooptação de Getúlio Vargas, de sua base de apoio político e militar. Num movimento imperativo e pragmático, políticos e militares escolheram transigir, negociar e aderir aos planos varguistas para poderem sobreviver, algo a que o grupo paulista não estava disposto naquele momento.

Com o regime do Estado Novo, veio a perseguição política aos seus opositores e Paulo Duarte foi obrigado a enfrentar seu segundo exílio ${ }^{15}$. Partiu rumo à Alemanha, já dominada pelo nazismo, desembarcando no porto de Hamburgo em dezembro de 1938. Poucos dias depois deixou a cidade de Hamburgo, passando por Colônia, Mannheim, e de lá seguiu para Paris, onde viveria pelos próximos quatro meses. Foram também para o exílio político alguns de seus companheiros da jornada política dos últimos cinco anos, período em que os paulistas estiveram à frente do governo de São Paulo, os membros do conhecido grupo político armandista, mencionado ao longo deste texto. Eram eles: Armando de Salles Oliveira, Júlio de Mesquita Filho, Luiz Piza, Otávio Mangabeira, Mário Brandt e Paulo Nogueira Filho. Esse grupo reduzido será o responsável por algumas ações tomadas contra a ditadura estado-novista durante o tempo do exílio. Ações que também serão relatadas por Duarte em suas memórias e documentadas para a constituição de seu arquivo.

\section{A CULTURA POLÍTICA DE OPOSIÇÃO A GETÚLIO VARGAS NAS MEMÓRIAS DE PAULO DUARTE}

autados pelas reflexões feitas, tomando como exemplo os relatos que Paulo Duarte fez
dos episódios que antecederam a deflagração do golpe de novembro de 1937, entendemos que a constituição de um arquivo e de uma produção memorialística ancorada naquele suporte nos indica que havia, da parte de Paulo Duarte, o desejo de ser lembrado, de ter um lugar assegurado na história do período de 1930-1945 e, até mesmo, a ambição de autodefesa na avaliação que faz de sua atuação nos acontecimentos políticos do período. Nesse 
sentido, a correspondência privada, artigos escritos em periódicos a respeito da atuação de um grupo em determinado período, discursos políticos, dossiês temáticos organizados, entre outros, constituem "um tipo de documento que combina exercícios de produção do "eu" e de persuasão política dos outros "e de si mesmo" (Gomes e Schmidt, 2009: 42).

Assim, com base na leitura das memórias produzidas por Paulo Duarte e nas consultas aos documentos do arquivo do memorialista, procuramos localizar seu desejo de persuadir o leitor, e a si mesmo, acerca de sua atuação política durante o governo de Getúlio Vargas (19301945) em dois pontos: o primeiro afirma sua trajetória profissional e pessoal como importante para a história do período e para e desenvolvimento do país; o segundo afirma sua coerência política e fidelidade de revolucionário, pois ele lutou ativa e incansavelmente contra Getúlio Vargas e, se não obteve sucesso, foi unicamente em razão da incapacidade de outros membros de seu grupo, que não se comportaram como verdadeiros revolucionários. No primeiro ponto, novamente identificamos sua vontade de assegurar seu lugar na história, ao ressaltar a "grandeza" do seu papel político e social. No que diz respeito ao segundo ponto, o da "ambição de autodefesa", a tentativa de justificar a participação em um governo que teve políticas de aproximação com Getúlio Vargas. Nos dois, o ponto comum de conexão é o viés antivarguista, sem concessões, constituindo, portanto, uma cultura política de oposição a Vargas, que deveria ser passada para a história por meio das memórias e do arquivo. Foge dos nossos objetivos remontar ao período do exílio durante o Estado Novo, mas ressaltamos que Paulo Duarte faz questão de registrar e documentar as ações propostas e articulações para reações contra Getúlio Vargas, situando-se no campo político de franca, intransigente e explícita oposição ao varguismo.

A memória de luta contra Getúlio Vargas, constantemente chamado de ditador por Duarte, percorrerá a escrita do memorialista ao longo dos nove tomos e expressará o sentimento de ressentimento também em relação aos outros membros do grupo armandista. 0 ressentimento, expressão dessa autodefesa, aparece nas memórias tanto no período que antecede o golpe de novembro de 1937, quanto no período posterior a ele. Paulo Duarte, ao fazer autoavaliação de sua participação nos projetos do grupo, considera-se como parte importante dele, como peça importante de todo o esquema de luta contra o varguismo. Ao ressaltarmos o viés antivarguista presente nas memórias e arquivos de Paulo Duarte, pareceu-nos ser essa a sua vontade ao desvincular as ações do grupo político armandista do governo Vargas, ao demarcar a posição política do grupo. É preciso lembrar, porém, que Paulo Duarte, embora afirme ter sido contra qualquer aproximação do grupo com Vargas, acabou cedendo e apoiando Armando de Salles Oliveira em sua decisão de compor com o governo central, exercendo, a propósito, cargos na administração pública nesse momento. Paulo Duarte tinha Salles Oliveira como uma liderança e, apesar de eles nem sempre estarem de acordo, as decisões deste último eram respeitadas. Nesse 
sentido, é visível sua autodefesa quanto ao apoio a Salles Oliveira quando este se aproximou de Getúlio Vargas. Fazendo posteriormente a autocrítica e crítica do grupo, e conhecendo o desfecho da história do grupo político paulista, ele procurou justificar tal aproximação e fazer a crítica aos posicionamentos tomados por Salles Oliveira, cruciais para o desfecho do jogo político, com a derrota do grupo e a efetivação do golpe de 1937.

\section{NOTAS}

10 Partido Constitucionalista foi fundado em fevereiro de 1934, após a extinção do Partido Democrático e as dissidências do Partido Republicano Paulista.

2 Refiro-me ao grupo de Armando de Salles Oliveira como comunidade política do jornal O Estado de S. Paulo pelo envolvimento de seus membros com o periódico. Armando de Salles Oliveira era casado com Raquel de Mesquita, filha de Júlio de Mesquita, diretor do jornal. Paulo Duarte foi redator nesse veículo e correspondente internacional durante seu segundo exílio, em 1938.

3 Este artigo é resultado da pesquisa de pós-doutorado que realizei no Fundo Paulo Duarte, com o financiamento do Conselho Nacional de Desenvolvimento Científico e Tecnológico (CNPq), sob a orientação da Professora Maria Stella Martins Bresciani.

40 dossiê a respeito de Armando de Salles Oliveira e sua vida política é composto de cartas trocadas entre o político e alguns membros do grupo armandista e políticos aliados, sobretudo com Vivaldo Coaracy, Arnon de Mello e Otávio Mangabeira. Contém ainda artigos jornalísticos e documentos referentes à organização da campanha presidencial de 1937.

50 dossiê sobre o Partido Constitucionalista está composto principalmente de recortes de jornais publicados durante a atuação do partido, entre fevereiro de 1934, data de sua fundação, e novembro de 1937, data de sua extinção mediante o golpe do Estado Novo.

6 Para um quadro mais amplo sobre a campanha eleitoral, o debate entre os candidatos, as alianças políticas estabelecidas e as estratégias de campanha do candidato Armando de Salles Oliveira, ver: Sousa, 2016.

70 dossiê sobre a campanha eleitoral encontra-se no arquivo. A pasta contém cartas, planos estratégicos e recortes de jornais.

8 De acordo com Paulo Duarte (1977), já era conhecido que o Plano Cohen não passava de "balelas anônimas que o Partido Integralista atribuiu aos comunistas e foram entregues às altas autoridades militares (não foram entregues, estas; as altas autoridades militares colaboraram na forjicação desses documentos, levada a cabo por um oficial integralista, o tenente Mourão)" (Duarte, 1977: 2). 
9 Cardoso de Melo Neto assumiu o governo de São Paulo por indicação de Armando de Salles Oliveira, que deixou o posto para lançar sua candidatura à presidência do país.

10 Todo o planejamento da visita de Armando de Salles Oliveira ao Norte e Nordeste do país encontra-se no arquivo Paulo Duarte. 0 projeto de promoção do candidato incluía uma excursão da Grande Companhia Paulista de Comédia pelas capitais do norte e do nordeste. A excursão da companhia teria a finalidade de apresentar um espetáculo de caráter "nacionalista, econômico e político". De acordo com o documento de planejamento da excursão: "um dos pontos principais de uma campanha política em favor de uma candidatura paulista é o de convencer-se o Brasil de que o Estado de São Paulo deseja firmemente a unidade nacional. Assim, destruir-se-á a pecha de separatista atribuída ao povo paulista, intriga política que será, fatalmente, uma das grandes armas a ser empregadas contra São Paulo durante a campanha" (Arquivo Paulo Duarte, PD/ASO, pasta 37, n. 228).

11 Durante a campanha eleitoral para a Assembleia Estadual Constituinte, em 1934, o caderno "Jornal do PC" era publicado diariamente. Já para a campanha às eleições presidenciais, teve publicação semanal. Para mais informações a respeito da campanha estadual de 1934, ver: Sousa, 2012.

12 No Arquivo Paulo Duarte se encontram documentos referentes à articulação entre o jornal O Estado de S. Paulo, que publicava o caderno Jornal do PC, e outros jornais de São Paulo e do Rio de Janeiro. Possivelmente o Partido Constitucionalista encomendava matérias pagas nos jornais e também a publicação semanal do Jornal do $P C$. No Rio de Janeiro, o responsável pela articulação com a imprensa era o jornalista Vivaldo Coaraci, membro do grupo armandista. 0 jornal $A$ Batalha era um dos que apoiavam a campanha armandista no Rio de Janeiro (Arquivo Paulo Duarte, PD/ASO, pasta 37, n. 201).

13 Francisco Negrão de Lima, deputado federal por Minas Gerais entre 1935 e 1937. Em outubro de 1937 teve início o que ficou conhecido como Missão Negrão de Lima, que consistia em uma viagem do deputado às regiões Norte e Nordeste para contatar os governadores dos seus estados, comunicando-Ihes os pontos básicos de uma possível mudança institucional e sondando suas posições a respeito de um possível golpe de estado (Ferreira, 2007).

14 Francisco Campos foi consultor geral da República entre os anos 1933 e 1937, sob o governo Vargas. Em 1936, a pedido deste, começou a elaborar a Constituição que seria instaurada com o golpe de 1937.

150 primeiro exílio enfrentado por Paulo Duarte foi com o fim da Revolução Constitucionalista de 1932. 


\section{REFERÊNCIAS BIBLIOGRÁFICAS}

BORGES, Vavy Pacheco. Anos 1930 e política. História e historiografia. In: FREITAS, Marcos César. Historiografia brasileira em perspectiva. São Paulo: Contexto, 1998.

BORGES, Vavy Pacheco. Getúlio Vargas e a Oligarquia Paulista: história de uma esperança e muitos desenganos. São Paulo: Brasiliense, 1979.

CAMARGO, Aspásia et al. O golpe silencioso. Rio de Janeiro: Rio Fundo, 1989.

COHEN, Ilka Stern. "Para onde vamos?" Alternativas políticas no Brasil (1930-1937). Tese (Doutorado) Universidade de São Paulo, São Paulo, 1997.

DOSSIÊ ARMANDO DE SALLES OLIVEIRA (ASO). Pasta 37, Documento n. 201. Campinas: Centro de Documentação Alexandre Eulálio, Unicamp. Fundo Paulo Duarte.

DOSSIÊ ARMANDO DE SALLES OLIVEIRA (ASO). Pasta 37, Documento n. 228. Campinas: Centro de Documentação Alexandre Eulálio, Unicamp. Fundo Paulo Duarte.

DUARTE, Paulo. Memórias: ofício de trevas. São Paulo: Hucitec, 1977. v. 6. 321 p.

DUARTE, Paulo. Memórias: raízes profundas. São Paulo: Hucitec, 1974. v. 1. 257 p.

FERREIRA, Oliveiros S. Elos Partidos: uma nova visão do poder militar no Brasil. São Paulo: HARBRA, 2007.

GOMES, Ângela de Castro; SCHMIDT, Benito. Apresentação. In: GOMES, Ângela de Castro; SCHMIDT, Benito (orgs.). Memórias e narrativas (auto)biográficas. Rio de Janeiro: Editora FGV, 2009.

HALBWACHS, Maurice. A memória coletiva. São Paulo: Centauro, 2004.

HAYASHI, Marli Guimarães. Paulo Duarte: um quixote brasileiro. São Paulo: Hucitec, 2010.

HEYMANN, Luciana. De "arquivo pessoal" a "patrimônio nacional": reflexões acerca da produção de "legados". Rio de Janeiro: CPDOC, 2005a.

HEYMANN, Luciana. Os fazimentos do arquivo Darcy Ribeiro: memória, acervo e legado. Estudos Históricos, Rio de Janeiro, v. 2, n. 36, p. 43-58, 2005b.

PANDOLFI, Dulce. Os anos 1930: as incertezas do regime. In: FERREIRA, Jorge; DELGADO, Lucília de Almeida (orgs.). O Brasil republicano. Rio de Janeiro: Civilização Brasileira, 2003. p. 13-37.

SANDES, Noé Freire. Memória, arquivo e ressentimento: as memórias de Paulo Duarte. Revista IHGB, Rio de Janeiro, ano 173, v. 455, p. 209-226, 2012.

SARLO, Beatriz. Tempo passado: cultura da memória e guinada subjetiva. São Paulo: Companhia das Letras; Belo Horizonte: UFMG, 2007.

SIRINELLI, Jean François. Os intelectuais. In: REMOND, René (coord.). Por uma história política. Rio de Janeiro: Ed. FGV, 2003. p. 231-270.

SOUSA, Carolina S. "Para que o Brasil continue": história e memória de um grupo derrotado na política nacional (1933-1945). Tese (Doutorado) - Departamento de História, Universidade de Brasília, Brasília, 2016. 
SOUSA, Carolina S. Política, a arte de lembrar e de esquecer. Dissertação (Mestrado em História do Brasil) Departamento de História, Universidade de Brasília, Brasília, 2012.

VARGAS, Getúlio. Diário (1930-1942). São Paulo: Siciliano; Rio de Janeiro: Fundação Getúlio Vargas, 1995. 2 v. 1257 p.

VESENTINI, Carlos Alberto. A teia do fato: uma proposta de estudo sobre a memória histórica. São Paulo: Hucitec, História Social, USP, 1997.

ZIOLI, Miguel. Paulo Duarte (1899-1984). Um intelectual nas trincheiras da memória. Tese (Doutorado em História) - Universidade Estadual Paulista "Júlio de Mesquita Filho", Assis, 2010.

\section{ANEXO}

DUARTE, Paulo. Memórias: apagada e vil mediocridade. São Paulo: Hucitec, 1976a. v. 5. 356 p.

DUARTE, Paulo. Memórias: e vai começar uma nova era. São Paulo: Hucitec, 1979. v. 9.323 p.

DUARTE, Paulo. Memórias: inteligência da fome. São Paulo: Hucitec, 1975. v. 2. 328 p.

DUARTE, Paulo. Memórias: miséria universal, miséria nacional e minha própria miséria. São Paulo: Hucitec, 1978a. v. 7. 331 p.

DUARTE, Paulo. Memórias: os mortos de Seabrook. São Paulo: Hucitec, 1976b. v. 4. 436 p.

DUARTE, Paulo. Memórias: selva oscura. São Paulo: Hucitec, 1976c. v. 3. 389 p.

DUARTE, Paulo. Memórias: vou-me embora pra passárgada. São Paulo: Hucitec, 1978b. v. 8. 339 p. 